\title{
A Comparative study of efficacy of Thiocolchicoside with Diclofenac vs Eperisone with Diclofenac in patients with back pain
}

\author{
Ambrish $\mathrm{S}^{1}$, Nagesh Raju $\mathbf{G}^{2}$, Dharmaraj $B^{3}$, Nagendra Gowda $\mathbf{M ~ R}^{4}$ \\ ${ }^{1}$ Dr. Ambrish S, Department of Orthopedics, ${ }^{2}$ Dr. Nagesh Raju G, Department of Pharmacology, ${ }^{3}$ Dr. Dharmaraj B, \\ Department of Pharmacology, ${ }^{4}$ Dr. Nagendra Gowda M R, Department of Community Medicine, all authors are affiliated \\ with Basaveshwara Medical College \& Hospital, Chitradurga, Karnataka 577502, India.
}

Address for Correspondence: Dr. Ambrish S, Email: nhimabindu2003@gmail.com

\begin{abstract}
Background: A number of drugs are available for the treatment of Low back pain (LBP) as per the available literature. This study was undertaken to compare the efficacy of Thiocolchicoside- diclofenac and Eperisone - diclofenac in patients with low back pain.Materials and Methods: A prospective, open labeled, randomized, comparative clinical study was conducted in order to establish the efficacy of Thiocolchicoside - diclofenac and Eperisone - diclofenac in patients with back pain. Thirty patients of either sex with back pain were randomly allocated to two groups to receive either Thiocolchicoside (4 $\mathrm{mg}$ )+Diclofenac (50mg) twice a day (Group A) or Eperisone (150 mg) Sustained Release+Diclofenac (100mg) preparation once a day (Group B).Results: The finger to floor distance was improved significantly after treatment with both the drugs for 7 days. There was a statistically significant difference in improvement of finger to floor distance of both the drugs and was marked in Group B. About $80 \%$ of the patients were normal after 7 days of treatment in Group B. The VAS scores and Global assessment scale had also shown the lower scores for group B compared to group A. Conclusion: The Eperisone with diclofenac was found to be more effective in terms of Finger floor distance and improvement in Lasegue's sign, VAS score and global assessment scale than Thiocolchicoside with Diclofenac.
\end{abstract}

Key words: Low back pain, Thiocolchicoside, Eperisone

\section{Introduction}

Low back pain (LBP) is an important symptom in orthopedics with $60-80 \%$ of the world population experiencing pain at some time in their life [1]. Back pain is second most common reason to visit a physician and is most common chronic pain syndrome in individual countries [2]. The annual incidence of low back pain is 10 - $15 \%$ and a point prevalence of $15-30 \%$ in adult population [3]. Low back pain is a common musculoskeletal symptom that may be either acute or chronic. It may be caused by a variety of diseases \& disorders that affect the lumbar spine. The most frustrating aspect in the treatment of back pain is that there are "no magic bullets"[4].

Muscle relaxants and non steroidal anti inflammatory drugs (NSAIDs) are shown to have a therapeutic utility in the management of painful spasms of low back pain [5]. But the muscle relaxants have the common side effect of sedation which limits their use which affects the daily activity and decreases the capacity of working [6]. The

Manuscript Received: $26^{\text {th }}$ February 2017

Reviewed: $4^{\text {th }}$ March 2017

Author Corrected: $11^{\text {th }}$ March 2017

Accepted for Publication: $18^{\text {th }}$ March 2017 inhibition of the neural activity and pain sensation results when the voltage gated sodium channels are blocked [7].

Eperisone is a centrally acting skeletal muscle relaxant that has been used in the treatment of muscle spasm \& spasticity. It inhibits the mono and multi synaptic spinal reflexes and may also have a vasodilator action $[4,8]$.

Thiocolchicoside is a semi synthetic derivative of the colchicoside which acts through GABA mediated mechanism which relaxes the spasm and relieves pain.

It is used in the symptomatic treatment of painful muscle spasm $[6,9]$.

The studies comparing the Thiocolchicoside- diclofenac and Eperisone - diclofenac in patients with back pain are scant in the world and in this part of the country.

Hence this study was undertaken with the aim of comparing the efficacy of Thiocolchicoside- diclofenac and Eperisone - diclofenac. 


\section{Materials and Methods}

A prospective, open labeled, randomized, comparative clinical study was undertaken in the department of Orthopaedics, Basaveshwara Medical College \& Hospital, Chitradurga among 60 in patients of back pain specially admitted for the purpose of the study. The study is in accordance with the principles of good clinical practice and declaration of Helsinki. An informed consent was obtained from all the patients enrolled for the study. Clearance from institutional ethical committee was obtained from the institutional ethics committee.

The study sample comprised of two groups each of 30 patients of either sex with back pain were randomly allocated to receive either Thiocolchicoside $(4 \mathrm{mg})$ +Diclofenac (50mg) twice a day (Group A) or Eperisone (150 mg) Sustained Release +Diclofenac (100mg) preparation once a day (Group B) by using computer generated random numbers.

Patients aged between $20-60$ years of age of either sex and with complaints of low back pain of acute onset due to muscle sprains and prolapsed disc were included in the study. Pregnant / lactating women, Pain associated with fractures, Head injury patients with back pain and patients with history of intake of opioid analgesics were excluded from the study.

Group A patients received Thiocolchicoside (4mg) + Diclofenac $(50 \mathrm{mg})$ twice a day for 7 days or Group B patients comprising of 30 patients with low back ache received Eperisone (150mg) Sustained Release +Diclofenac (100mg) preparation once a day.

The ward staff nurse was advised to ensure by observing the patient swallowing the tablet in order to assess the patient compliance. The patients admitted were not advised with any other modalities of treatment.

\section{Results}

Table-1:Socio demographic variables of the study.

\begin{tabular}{|c|c|c|c|c|}
\hline & Group A & Group B & Test value & P value, Sig \\
\hline Age (Mean + SD) & $48.9 \pm 8.52$ & $51.17 \pm 8.15$ & T value $=1.053$ & 0.297, NS \\
\hline Males, n (\%) & $18(60.0)$ & $16(53.3)$ & \multirow{2}{*}{$\chi^{2}$ value $=0.271$} & 0.602, NS \\
\cline { 1 - 3 } Females, n (\%) & $12(40.0)$ & $14(46.7)$ & & \\
\hline
\end{tabular}

The mean age of the Group A patients was 48.9 ( \pm 8.52$)$ years and group B was $51.17(( \pm 8.15)$ years. There was no statistically significant difference between the two groups ensuring the comparability between the two groups.

Most of the study subjects in both the group were males. The difference between the sex of both the groups was not statistically significant also ensuring the comparability. 
Table-2: Finger to floor distance of the study group.

\begin{tabular}{|c|c|c|c|c|}
\hline & Group A & Group B & T value & P value, Sig \\
\hline Day 1 & $24.3 \pm 11.41$ & $16.6 \pm 13.454$ & 2.402 & 0.02, Sig \\
\hline Day 7 & $6.83 \pm 3.63$ & $2.67 \pm 2.155$ & 5.403 & 0.000, Sig \\
\hline T value & 9.916 & 20.421 & & \\
\hline P value, Sig & 0.000, Sig & 0.000, Sig & & \\
\hline
\end{tabular}

The mean finger to floor distance of group A patients on day 1 was $24.3( \pm 11.41) \mathrm{cm}$ and on day 7 was $6.83( \pm 3.63) \mathrm{cm}$. This difference was statistically significant between day 1 and day 7. The mean finger to floor distance of Group B patients on day 1 was $16.6( \pm 3.454) \mathrm{cm}$ and day 7 was $2.67( \pm 2.155) \mathrm{cm}$. This difference was also statistically significant between the day 1 and day 7. The difference in finger to floor distance was statistically significant on day 7 favoring Group B patients.

Table-3:Lasegues sign of the study group at day $1 \& 7$.

\begin{tabular}{|c|c|c|c|c|}
\hline \multirow[t]{2}{*}{ Laseague's sign } & \multicolumn{2}{|c|}{ Day 1} & \multicolumn{2}{|c|}{ Day 7} \\
\hline & $\begin{array}{c}\text { Group A } \\
\text { n (\%) }\end{array}$ & $\begin{array}{c}\text { Group B } \\
\text { n (\%) }\end{array}$ & $\begin{array}{c}\text { Group A } \\
\text { n (\%) }\end{array}$ & $\begin{array}{c}\text { Group B } \\
\text { n (\%) }\end{array}$ \\
\hline Normal & $5(16.7)$ & $7(23.3)$ & $14(46.7)$ & $24(80.0)$ \\
\hline Mild hypertonia & $5(16.7)$ & $14(46.7)$ & $13(43.3)$ & $6(20.0)$ \\
\hline Moderate hypertonia & $14(46.7)$ & $6(20.0)$ & $3(10.0)$ & 0 \\
\hline Marked hypertonia & $6(20.0)$ & $3(10.0)$ & 0 & 0 \\
\hline Total & $30(100)$ & $30(100)$ & $30(100)$ & $30(100)$ \\
\hline$\chi^{2}$ value $=8.796 \quad \mathrm{df}=3$ & \multicolumn{2}{|c|}{$P$ value $=0.032$, Sig } & $\chi^{2}$ value $=8.211 \mathrm{df}=2$ & $P$ value $=0.016$, Sig \\
\hline
\end{tabular}

In group A on day 1 , about $46.7 \%$ of the patients of group A had moderate hypertonia and $46.7 \%$ of the group B patients had mild hypertonia. There was a statistically significant difference between the lasegue's sign of the group A and group B on day 1.At the end of day 7 , about $46.7 \%$ of the Group A patients and $80 \%$ of the Group B patients were normal by lasegue's sign. This difference in tone by Lasegue's sign was statistically significant between the two groups.

Table-4: Visual Analogue score of the study group.

\begin{tabular}{|c|c|c|c|c|}
\hline & Group A & Group B & T value & P value, Sig \\
\hline Day 1 & $6.37 \pm 1.63$ & $6.43 \pm 1.79$ & 0.151 & $0.881, \mathrm{NS}$ \\
\hline Day 7 & $2.17 \pm 1.31$ & $1.33 \pm 1.63$ & 2.183 & 0.033, Sig \\
\hline T value & 5.99 & 16.155 & & \\
\hline P value, Sig & $0.000, \mathrm{Sig}$ & $0.000, \mathrm{Sig}$ & & \\
\hline
\end{tabular}

The mean VAS score of Group A patients was $6.37( \pm 1.63)$ which was reduced to $2.17( \pm 1.31)$ which was statistically significant between day 1 to day 7. The mean VAS score of Group B patients on day 1 was $6.43( \pm 1.79)$ which was reduced to $1.33( \pm 1.63)$ on day 7 . This difference was statistically significant. The VAS scores were statistically significant between the two groups on day 7 .

Table-5: Distribution of the study group according to Global scale.

\begin{tabular}{|c|c|c|}
\hline Lasegue's sign - Day 7 & $\begin{array}{c}\text { Group A } \\
\text { n (\%) }\end{array}$ & $\begin{array}{c}\text { Group B } \\
\text { n (\%) }\end{array}$ \\
\hline Poor & $1(3.3)$ & $2(6.7)$ \\
\hline Average & $10(33.3)$ & $1(3.3)$ \\
\hline Good & $18(60.0)$ & $13(43.3)$ \\
\hline Excellent & $1(3.3)$ & $14(46.7)$ \\
\hline Total & $30(100)$ & $30(100)$ \\
\hline
\end{tabular}

$\chi^{2}$ value $=19.77 \quad \mathrm{df}=3 \quad$ P value $=0.000$, Sig


The global assessment scale has indicated that about $33.3 \%$ of the patients in group A had the average grade and $60 \%$ had good grade among Group A patients. Among the Group B patients, 43.3\% of the patients were graded as good and 46.7\% were graded as excellent. This difference in grading of Global scale was statistically significant between group A and Group B.

\section{Discussion}

This study was conducted to compare the efficacy of Thiocolchicoside with diclofenac and Eperisone with diclofenac. The main goal of the pharmacological intervention in low back pain is not only relief from the pain but also to reduction of the muscle spasm and inflammation. Eperisone is a muscle relaxant which in addition to inhibition of mono and multi synaptic reflexes also regulates the blood supply to the skeletal muscles [13]. Thiocolchicoside being a spinal GABA agonist compound has been reported to exert inhibitory effect and result in muscle relaxation [14]. Unlike other muscle relaxants, these drugs have been reported to have less gastro intestinal side effects and sedative effects [15].

This study had shown that, the finger to floor distance was improved by $71.9 \%$ in Thiocolchicoside group and $83.9 \%$ in the Eperisone group which was statistically significant.

A study by Cabitza et al had shown to improve the FFD more in Eperisone group similar to the results of this study after 7 days of treatment [9]. Maaz et al [16] have also supported the results of Cabitza et al. In contrary to these results, Rao et al [17] and Soonawala et al reported Thiocolchicoside is a better drug of choice in comparison with Eperisone [18].

The lasegue's sign was improved in both groups but it was marked in Eperisone group. About $46.7 \%$ of the patients in Thiocolchicoside group had the moderate hypertonia improved to normal in $46.7 \%$ of the patients after 7 days of treatment. In the Eperisone group, about $46.7 \%$ of the patients had mild hypertonia which improved to normal in $80 \%$ of the patients. There was a statistically significant between the two groups. Cabitza et al [9] and Maaz et al [16] have also reported that the VAS score of pain decreased significantly in patients receiving Thiocolchicoside and Eperisone. A study by Frandisco et al [19] and Soonawala et al[18] have also reported that both Eperisone and Thiocolchicoside decrease the muscle spasm.

The global assessment scale has indicated that $60 \%$ had good grade in Thiocolchicoside group and $46.7 \%$ were graded as excellent in the Eperisone group. This difference in grading of Global scale was statistically significant between the two groups. No studies have reported the findings of Global assessment and hence these study results were not compared with other studies.
The adverse effects in the study were negligible and hence were not reported. The usual gastro intestinal side effects due to diclofenac have been reported and treated appropriately by using proton pump inhibitors.

\section{Conclusion}

Although Thiocolchicoside with diclofenac and Eperisone with Diclofenac are found to effective drugs in relieving the Lower back pain, Eperisone with Diclofenac was found to be more effective in terms of Finger floor distance and improvement in Lasegue's sign, VAS score and global assessment scale.

Conflict of interest: None declared.

Funding: Nil, Permission from IRB: Yes

\section{References}

1. Doherty M, Laryon P, Ralston SH. Presenting problems in musculoskeletal diseases; Back \& neck pain. In: Boon NA, Colledge NR, Walker BR. Davidson's The Principle \& Practice of Medicine Churchill Livingstone, Elsevier London, Edition 20;2006:1083-84.

2. Panchapakesa RC. Low back pain. In: Shah SN, Paul AN,; API Text book of Medicine. The Association of Physician of India, Mumbai Edition 7;2007:1148-1151.

3. Moore RA, Straube S, Derry S, McQuay HJ. Chronic low back pain analgesic studies--a methodological minefield. Pain. 2010 Jun;149 (3):431-4. doi: 10.1016/j. pain. 2010.02.032. Epub 2010 Mar 20.

4. Chandanwale AS, Chopra A, Goregaonkar A, Medhi B, Shah V, Gaikwad S, Langade DG, Maroli S, Mehta SC, Naikwadi A, Pawar DR. Evaluation of eperisone hydrochloride in the treatment of acute musculoskeletal spasm associated with low back pain: a randomized, double-blind, placebo-controlled trial. J Postgrad Med. 2011 Oct-Dec; 57(4): 278-85. doi: 10. 4103 /0022-3859. 90076.

5. Chandanwale AS, Chopra A, Goregaonkar A et al. Evaluation of eperisone hydrochloride in the treatment of acute musculoskeletal spasm associated with low back pain: a randomized, double-blind, placebo-controlled trial. J Postgrad Med. 2011 Oct-Dec; 57(4):278-85. doi: 10. 4103/0022-3859.90076. 
Original Research Article

6. Burton AK, Balagué F, Cardon G, Eriksen HR, Henrotin Y, Lahad A, Leclerc A, Müller G, van der Beek AJ; COST B13 Working Group on Guidelines for Prevention in Low Back Pain. Chapter 2. European guidelines for prevention in low back pain : November 2004. Eur Spine J. 2006 Mar;15Suppl 2:S136-68.

7. Ketenci A, Ozcan E, Karamursel S. Assessment of efficacy and psychomotor performances of thiocolchicoside and tizanidine in patients with acute low back pain. Int J ClinPract. 2005 Jul; 59(7):764-70.

8. Maaz SH, Khandelwal PN, Baig SM, Doifode SM, Ghotkar UM, Evaluation of the efficacy and tolerability of eprisone and thocolchicoside in treatment of low back pain associated with muscle spasm: A open label, prospective, randomized control trial, IJBP: 2016: November-December: 6: 2669.

9. Gold MS. $\mathrm{Na}(+)$ channelblockers for the treatment of pain: context is everything, almost. Exp Neurol. 2008 Mar; 210(1):1-6. doi: 10.1016/j.expneurol.2007.12.001. Epub 2007 Dec 8.

10. Cabitza P, Randelli P. Efficacy and safety of eperisone in patients with low back pain: a double blind randomized study. European Review for Medical and Pharmacological Sciences. 2008;12:229- 35

11. Hawker GA, Mian S, Kendzerska T, French $M$. Measures of adultpain: Visual Analog Scale for Pain (VASPain), Numeric RatingScale for Pain (NRSPain), McGill Pain Questionnaire (MPQ), Short-FormMcGill Pain Questionnaire (SF-MPQ), Chronic PainGradeScale (CPGS), Short Form-36 Bodily PainScale (SF-36BPS), and Measure of Intermittent and Constant Osteoarthritis Pain (ICOAP). ArthritisCare Res (Hoboken). 2011 Nov; 63Suppl 11: S240-52. doi: 10.1002/acr.20543.

12. Nikiphorou E, Radner $\mathrm{H}$, Chatzidionysiou $\mathrm{K}$, Desthieux C, Zabalan C, van Eijk-Hustings Y, Dixon WG, Hyrich KL, Askling J, Gossec L. Patient globalassessment in measuring diseaseactivity in rheumatoid arthritis: a review of the literature. Arthritis ResTher.2016 Oct 28;18(1):251.
13. Magnusson SP, Simonsen EB, Aagaard P, Boesen J, Johannsen F, Kjaer M. Determinants of musculoskeletal flexibility: viscoelasticproperties, cross-sectionalarea, EMG and stretchtolerance. Scand J Med Sci Sports. 1997 Aug;7(4):195-202.

14. Chou R. Pharmacological management of low back pain.Drugs. 2010 Mar 5;70(4):387-402 doi: $10.2165 /$ 11318690-000000000-00000.

15. Umarkar AR, Bavaskar SR, Yewale PN. Thiocolchicoside as muscle relaxant: a review. International Journal of Pharmacy and Biological Sciences 2011;1(3):364-71.

16. Tanaka K, Kaneko T, Yamatsu K. [Effects of 4'ethyl2-methyl-3-piperidinopropiophenone on experimental rigidity and spinal cord activities (author's transl)]. Nihon YakurigakuZasshi. 1981 May;77(5):511-20.

17. Maaz SH, Khandelwal PN, Baig SM, Doifode SM, Ghotkar UM. Evaluation of efficacy and tolerability of eperisone and thiocolchicoside in treatment of low back pain associated with muscle spasm: An open label, prospective, randomized controlled trial. Int $\mathrm{J}$ Basic Clin Pharmacol 2016;5:2669-74.

18. Rao R, Panghate A, Chandanwale A, Sardar I, Ghosh M, Roy M, Banerjee B, Goswami A, Kotwal PP. Clinicalcomparative study: efficacy and tolerability of tolperisone and thiocolchicoside in acute low back pain and spinalmuscle spasticity. Asian Spine J. 2012 Jun; 6 (2): 115-22. doi: 10.4184/asj.2012.6.2.115. Epub 2012 May 31.

19. Soonawalla DF, Joshi N. Efficacy of thiocolchicoside in Indian patients suffering from low back painassociated with muscle spasm. J Indian Med Assoc. 2008 May;106 (5):331-5.

20. Frandisco CR, Ramon VP, Enrique RB, Francisco FB. Effect of two different doses of Eperisone in treatment of acute low back pain. The J of Applied Research. 2009; 9(1):23-9.

\section{How to cite this article?}

Ambrish S, Nagesh Raju G, Dharmaraj B, Nagendra Gowda M R. A Comparative study of efficacy of Thiocolchicoside with Diclofenac vs Eperisone with Diclofenac in patients with back pain. Int $J$ surg Orthopedics 2017;3(1):1-5. doi:10.17511/ijoso.2017.i01.01. 